\title{
Socio- economic profile of dairy farmers in Hisar district of Haryana
}

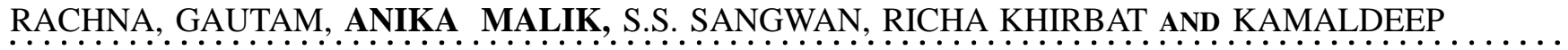

Author for Corresponding -

ANIKA MALIK

Department of Veterinary and Animal Husbandry Extension

Education, College of Veterinary

Sciences, Lala Lajput Rai

University of Veterinary and

Animal Sciences, HISAR

(HARYANA) INDIA

Email: anikadhundwal@gmail.com

See end of the article for

Coopted authors'

\begin{abstract}
Among the different forms of livestock farming, dairying is considered as a "treasure" of the Indian rural economy. For the design and implementation of support programmes to promote dairy farming for rural development and for adoption of new technologies in dairy, profile of the dairy farmers is an important factor in developing countries like India. By considering this aspect the study was undertaken in Hisar district of Haryana. Among the 60 dairy farmers 73.3 per cent of respondents were middle aged with mean age of about 43 years. The respondents had fairly good formal education with mean value of 4.23 which indicates that majority (96.6\%) of dairy farmers were literate. Family structure of dairy farmers was 65.0 per cent of the respondents belonged to joint families and 35.0 per cent to nuclear families. The family land holding ranged from 1 to 6 acres with a mean 2.60 acres. 43.3 per cent of the respondents preferred to have a herd size of 3-5 dairy animals. The respondents in general had poor social participation with mean value as low as 0.16 . Further, majority of the respondents had low level of extension contact with mean value of 2.23. Mass media exposure of dairy farmers was also low with mean value of 2.65 which indicates majority $(73.3 \%)$ of dairy farmers had low level of mass media exposure. However, economic motivation of dairy farmer was fairly high with mean value of 22.56 . The dairy farmers in general had medium risk orientation with mean value 18.28 .
\end{abstract}

KEY WORDS....... Dairy farmers, Socio-economic profile, Dairying, Rural development, Livestock farming

HOW TO CITE THIS ARTICLE - Rachna, Gautam, Malik, Anika, Sangwan, S.S., Khirbat, Richa and Kamaldeep (2017). Socio-economic profile of dairy farmers in Hisar district of Haryana. Asian J. Animal Sci., 12(1): 88-94. DOI : 10.15740/HAS/TAJAS/12.1/88-94.

ARTICLE CHRONICLE - Received : 26.04.2017; Accepted : 30.05.2017 